\title{
TINJAUAN YURIDIS TINDAK PIDANA PENIPUAN STUDI KASUS PUTUSAN PERKARA NOMOR 482/Pid.B/2018/PN Blt
}

\author{
Rex Richard Sanjaya, Weppy Susetiyo; Fakultas Hukum Universitas Islam Balitar, Blitar, \\ Jawa Timur; E-mail: berkasonghenpen@gmail.com
}

\begin{abstract}
Abstrak
Demi terwujudnya kepastian hukum materiil yang mengatur mengenai pelaku tindak pidana, aparat penegak hukum khususnya jaksa dan hakim harus memperhatikan secara cermat dan jelas mengenai unsur-unsur dalam setiap pasal, karena jika salah dalam menerapkan pasal maka hal tersebut batal demi hukum. Penelitian yuridis normatif dengan data sekunder Putusan Perkara Nomor 482/Pid. B/2018/PN Blt. menunjukkan bahwa Surat dakwaan dan tuntutan (requisitoir) yang dibuat oleh Penuntut Umum dengan Nomor Registrasi Perkara PDM 201/BLTAR/Epp.2/12/2018 sudah memenuhi syarat formal dan materiil sesuai Pasal 143 Ayat (2) KUHAP.

Kata kunci: Putusan Pengadilan, Tindak pidana, Penipuan

\section{Abstract}

For the sake of the realization of the material legal certainty that governs the perpetrators of crime, law enforcement officials, especially prosecutors and judges must pay careful attention and clearly about the elements in each article, because if it is wrong in applying the article then it is null and void. Normative juridical research with secondary data on Case Decision Number 482 / Pid. B / 2018 / PN Blt. shows that the indictment and claim (requisitoir) made by the Public Prosecutor with PDM Case Registration Number 201 / BLTAR / Epp.2 / 12/2018 have met the formal and material requirements in accordance with Article 143 Paragraph (2) of the Criminal Procedure Code.
\end{abstract}

Keywords: Court Decision, Crime, Fraud

\section{PENDAHULUAN}

\section{Latar Belakang}

Pada dasarnya kita semua menginginkan untuk mencari nafkah dengan cara yang halal. Seperti berdagang, menjadi karyawan, ataupun menciptakan usaha sendiri. Namun ada juga orang yang mencari nafkah dengan cara yang tidak benar. Salah satu penyebab orang melakukan hal ini adalah karena semakin modern hidup semakin sulit. Apapun dilakukan agar kebutuhan terpenuhi. Baik pribadi maupun kelompok. Kendati demikian mereka menggunakan cara yang jelas dilarang oleh hukum.

Salah satu tindakan yang dilarang dan tidak sejalan dengan hukum adalah penipuan. Penipuan menurut Kamus Besar Bahasa Indonesia yaitu, berasal dari kata dasar tipu adalah perbuatan atau perkataan yang tidak jujur (bohong, palsu, dan sebagainya) dengan maksud untuk menyesatkan, mengakali atau mencari untung. Sedangkan penipuan adalah proses, perbuatan atau cara menipu. ${ }^{1}$

Penipuan sangat marak terjadi, boleh dibilang hal yang umum di zaman sekarang, karena perbuatan ini sangat mudah untuk dilakukan. Cukup yakinkan korban dengan kata bohong atau tipu muslihat agar korban mengikuti apapun yang diinginkan si pelaku. Kenyataan membuktikan bahwa tindak pidana penipuan seringkali

\footnotetext{
${ }^{1}$ Tim Penyusun Kamus Pusat Pembinaan dan Pengembangan Bahasa, Kamus Besar Bahasa Indonesia, Jakarta: Balai Pustaka, 1990, h. 952.
} 
dipersamakan dengan ingkar janji dalam hukum perdata (wanprestasi), sehingga penegak hukum, utamanya penuntut umum seringkali keliru dalam menentukan mana yang merupakan tindak pidana penipuan atau wanprestasi dalam membuat surat dakwaan, sehingga tidak jarang Majelis Hakim memutus lepas perkara yang dianggap sebagai tindak pidana penipuan oleh penuntut umum, akan tetapi sebenarnya perbuatan tersebut merupakan wanprestasi hukum perdata.

Penipuan merupakan salah satu kejahatan yang mempunyai objek terhadap harta benda. Dalam arti luas diatur dalam bab XXV tentang Perbuatan Curang dan dari Pasal 378 sampai Pasal 395 Kitab Undang-Undang Hukum Pidana (KUHP), sehingga di dalam KUHP peraturan mengenai tindak pidana penipuan ini merupakan tindak pidana yang paling panjang pembahasannya diantara kejahatan terhadap harta benda lainnya. ${ }^{2}$

Tindak pidana penipuan merupakan suatu delik biasa, artinya ketika terjadi penipuan, siapapun dapat melaporkan kejadian tersebut kepada aparat kepolisian, beda dengan delik aduan yang dapat diproses hanya bila korban melakukan pengaduan kepada aparat setempat yang berwenang. Laporan dari delik biasa dapat dilaporkan ke kepolisian setempat yang berwenang, kemudian kepolisian akan melakukan penyidikan sesuai dengan laporan tersebut, menganalisa bilamana adalah tindak pidana yang dilaporkan. Setelah penyelidikan dilakukan, dan benar bahwa kejadian tersebut adalah tindak pidana, maka proses penyelidikan mengalami tahap baru menjadi proses penyidikan.

Pada proses penyidikan, penyidik akan mengumpulkan bukti-bukti yang mendukung agar kelak apabila bukti dirasa cukup, berkas perkara tersebut diserahkan ke jaksa penuntut umum. Tugas penyidik berhenti sampai disini. Selanjutnya Jaksa Penuntut Umum menulis surat dakwaan yang akan dilimpahkan ke pengadilan untuk diperiksa, diadili serta diputus oleh pengadilan negeri.

\section{Rumusan Masalah}

Berdasarkan latar belakang masalah yang telah diuraikan tersebut, maka pokok permasalahan pada penelitian ini adalah :

1. Bagaimanakah penerapan hukum pidana materiil pada perkara tindak pidana penipuan (Studi Kasus Putusan No. 482/Pid.B/2018/PN Blt)?

2. Bagaimanakah pertimbangan hukum hakim untuk menjatuhkan pidana terhadap pelaku tindak pidana penipuan (Studi Kasus Putusan No. 482/Pid.B/2018/PN Blt)

\section{METODE PENELITIAN}

Penelitian yuridis normatif ini menggunakan sumber data primer, yang merupakan data yang dikumpulkan dengan cara mendalami literatur pustaka seperti buku-buku, undang-undang, laporan penelitian, serta berbagai referensi kepustakaan lainnya, dengan metode penelitian yaitu metode penelitian kepustakaan dan metode penelitian

\footnotetext{
2 Adirwan Akbar, Tinjauan Yuridis terhadap Tindak Pidana Penipuan (Studi Kasus Putusan No. 1629/Pid.B/2014/PN.Mks.), Universitas Hasanuddin, Makassar, 2015, h. 3.
} 
lapangan. Selanjutnya, setiap data yang telah diperoleh akan dianalisis dan diproses menggunakan metode kualitatif sehingga dapat ditarik sebuah kesimpulan.

\section{HASIL PENELITIAN DAN PEMBAHASAN}

\section{Penerapan Hukum Pidana Materiil dalam Perkara Tindak Pidana Penipuan (Studi Kasus Putusan Nomor: 482/Pid.B/2018/PN Blt)}

Posisi kasus dan penjatuhan putusan oleh Majelis Hakim dalam acara pemeriksaan biasa pada Pengadilan Negeri Blitar yang telah memeriksa dan mengadili perkara dengan Putusan Nomor: 482/Pid.B/2018/PN Blt adalah sebagai berikut:

Berawal dari Nanda Irawan berkenalan dengan Leni melalui akun Facebook kemudian dilanjutnya dengan Whatsap (WA) lalu mereka saling chat. Setelah berkomunikasi dengan Nanda Irawan, Leni menghubungi Nanda Irawan bersama dengan Kasturi Bagus Wijayanto. Setelah terdakwa komunikasi dengan Nanda Irawan kemudian handphone ( $\mathrm{Hp}$ ) milik terdakwa dipegang oleh Kasturi Bagus Wijayanto dan digunakan untuk menghubungi Nanda Irawan untuk memancing korban agar mau bertemu dengan Leni seolah-olah yang berkomunikasi adalah Leni. Setelah Nanda Irawan membalas semua WA yang ditulis oleh Kasturi Bagus Wijayanto melalui Hp terdakwa yang isinya antara lain janjian akan bertemu dengan terdakwa.

Kesepakatan Leni bertemu dengan Nanda Irawan dilakukan pada hari Kamis tanggal 25 Oktober 2018 sekitar pkl 22.00 WIB di simpang empat Jln Madura. Selanjutnya mereka dengan mengendarai sepeda motor Honda Mega Pro No Pol AG 5734 KBF tahun 2008 Noka MH1KC12118K082343 Nosin KC12E1082906 menuju ke Café Muscle depan pom bensin di Jalan Kalimantan Kota Blitar.

Di tempat tersebut Nanda Irawan bersama dengan terdakwa pesan minuman dan ngobrol selama 30 menit, lalu terdakwa bilang kepada Nanda Irawan "Saya pinjam motor sebentar untuk mengambil kunci kamar kost selama 5 menit" tetapi Nanda Irawan mengatakan "Tidak boleh" lalu terdakwa kembali mengatakan " Ayoto sebentar aja" kemudian Nanda Irawan memberikan kunci motornya dan motor Nanda dibawa pulang oleh Leny ke kosnya. Selanjutnya pada hari Jumat tanggal 26 Oktober 2018 sekitar pkl 08.00 WIB Kasturi Bagus Wijayanto melepasi lampu belok (reting/sen) bagian belakang dan depan serta plat nomor kendaraan Honda Mega Pro No Pol AG 5734 KBF milik Nanda Irawan dan Leni bertanya kepada Kasturi Bagus Wijayanto dengan kata kata "Kenapa plat dan retingnya dilepas?" dan kemudian dijawab oleh Kasturi Bagus Wijayanto dengan kata-kata "Yang punya biar tidak tahu kalau ini motornya".

Bahwa sepeda motor tersebut rencananya akan dijual dan uangnya digunakan untuk memenuhi kebutuhan sehari-sehari. Saat saksi Nanda Irawan melintas di Jln Enggano melihat sepeda motor miliknya diparkir di depan sebuah kost kemudian saksi berhenti dan untuk memastikan apakah sepeda motor Honda Mega Pro tersebut miliknya setelah mengecek sepeda motor tersebut selanjutnya Nanda Irawan ke Polsek Sananwetan untuk memberitahukan keberadaan sepeda motor Honda Mega Pro miliknya yang telah dibawa terdakwa. 


\section{Analisis Penerapan Hukum Pidana Materiil}

Surat dakwaan memuat uraian fakta-fakta yang terjadi, uraian yang menjelaskan unsur-unsur yuridis dari pasal-pasal tindak pidana yang dilanggar. Dalam kasus ini pasal tindak pidana yang dilanggar yaitu Pasal 378 KUHP tentang Penipuan. Sedangkan arti penting dari surat dakwaan ialah: ${ }^{3}$

1. Bagi penuntut umum :

a. Dasar penuntutan perkara ke pengadilan.

b. Dasar untuk pembuktian dan pembahasan juridis

dalam tuntutan pidana (requisitoir).

c. Dasar untuk melakukan upaya hukum.

2. Bagi terdakwa/penasehat hukum :

Surat dakwaan merupakan dasar untuk melakukan pembelaan dengan menyiapkan bukti-bukti kebalikan terhadap apa yang didakwakan oleh penuntut umum.

3. Bagi hakim :

a. Dasar pemeriksaan di persidangan

b. Pedoman untuk mengambil keputusan yang akan dijatuhkan kepada terdakwa.

Penuntut Umum dalam membuat surat dakwaan harus berpedoman pada Pasal 143 Ayat (2) KUHAP. Pada Pasal 143 Ayat (2) KUHAP diatur mengenai syarat formal (143 Ayat (2) huruf a KUHAP) dan syarat materiil (143 Ayat (2) huruf b KUHAP) yang harus dipenuhi oleh Penuntut Umum dalam membuat surat dakwaan. Apabila syarat materiil dari surat dakwaan tidak dipenuhi oleh Penuntut Umum, maka surat dakwaan tersebut batal demi hukum (Pasal 143 Ayat (3) KUHAP), sedangkan apabila syarat formalnya tidak dipenuhi, maka surat dakwaan dapat dibatalkan. Adapun syarat - syarat formal (143 Ayat (2) huruf a KUHAP) dan materiil (143 Ayat (2) huruf b KUHAP) surat dakwaan sebagaimana diatur dalam KUHAP ialah :

a. nama lengkap, tempat lahir, umur atau tanggal lahir, jenis kelamin, kebangsaan, tempat tinggal, agama dan pekerjaan tersangka ;

b. uraian secara cermat, jelas dan lengkap mengenai tindak pidana yang didakwaan dengan menyebutkan waktu dan tempat tindak pidana itu dilakukan.

Maksud dari cermat, jelas dan lengkap seperti yang diatur dalam Pasal 143 Ayat (2) huruf b KUHAP adalah :4

1. Cermat: ketelitian Penuntut Umum dalam mempersiapkan surat dakwaan yang didasarkan kepada Undang-Undang yang berlaku bagi terdakwa, tidak terdapat kekurangan atau kekeliruan yang dapat mengakibatkan batalnya surat dakwaan atau dakwaan tidak dapat dibuktikan. Misalnya, adakah pengaduan dalam hal delik aduan, apakah terdakwa dapat dipertanggungjawabkan melakukan tindak pidana tersebut, apakah tindak pidana tersebut belum/sudah kadaluarsa atau apakah tindak pidana tersebut tidak nebis in idem.

\footnotetext{
${ }^{3}$ Hari Sasangka dan Lily Rosita, Hukum Pembuktian dalam Perkara Pidana, Bandung: Mandar Maju, 2003, h. 3.

${ }^{4}$ Bambang Waluyo, Pidana dan Pemidanaan, Jakarta: Sinar Grafika, 2004, h. 65.
} 
2. Jelas: Penuntut Umum harus mampu merumuskan unsur-unsur delik yang didakwakan sekaligus memadukan dengan uraian perbuatan materiil (fakta) yang dilakukan terdakwa dalam surat dakwaan.

3. Lengkap: uraian dakwaan harus mencakup semua unsur yang ditentukan UndangUndang secara lengkap.

Dakwaan yang ditulis oleh Penuntut Umum pada kasus ini dengan Nomor Registrasi Perkara : PDM- 201 / BLTAR / Epp.2 / 12 / 2018 bila dihubungkan dengan syarat-syarat formal dan materiil perihal menulis surat dakwaan seperti yang telah ditentukan dalam Pasal 143 Ayat (2) KUHAP, maka surat dakwaan ini telah memenuhi syarat formal sesuai Pasal 143 Ayat (2) huruf a KUHAP, yakni telah dicantumkannya nama lengkap, tempat lahir, umum atau tanggal lahir, jenis kelamin, kebangsaan, tempat tinggal, agama dan pekerjaan tersangka dalam surat dakwaan. Sedangkan mengenai perihal syarat materiil, surat dakwaan tersebut juga telah memenuhi syarat materiil dalam membuat surat dakwaan sebagaimana yang diatur pada Pasal 143 Ayat (2) huruf b KUHAP. Dalam kasus ini, surat dakwaan dengan Nomor Registrasi Perkara : PDM- 201 / BLTAR / Epp.2 / 12 / 2018 yang dibuat oleh Penuntut Umum membagi menjadi 3 unsur Pasal 378 KUHP, yaitu :

1. Barang siapa.

2. Dengan maksud untuk menguntungkan diri sendiri atau orang lain secara melawan hukum.

3. Dengan memakai nama palsu, dengan tipu muslihat ataupun rangkaian kebohongan menggerakkan orang lain untuk menyerahkan barang sesuatu kepadanya atau supaya memberi hutang atau menghapuskan piutang.

Surat dakwaan dalam kasus ini, ketika dirancang oleh Penuntut Umum, Penuntut Umum telah mampu memenuhi seluruh unsur materiil sesuai yang dicantumkan dalam Pasal 143 Ayat (2) huruf b KUHAP, yakni cermat, jelas, lengkap dan juga sudah disertakan pada surat dakwaan dengan Nomor Registrasi Perkara PDM- 201/BLTAR/ Epp. 2/12/2018. Petunjuk untuk menjabarkan unsur-unsur materiil (cermat, jelas, lengkap) dari surat dakwaan sendiri tidak diatur dengan jelas di dalam KUHAP, sehingga Penuntut Umum ketika merancang surat dakwaan bebas untuk menjabarkan unsur-unsur tersebut selama masih memenuhi syarat materiil sesuai dengan yang dibatasi oleh Pasal 143 Ayat (2) huruf b KUHAP.

\section{Pertimbangan Hukum Hakim dalam Menjatuhkan Pidana terhadap Pelaku Tindak Pidana Penipuan (Studi Kasus Putusan Nomor: 482/Pid.B/2018/PN Blt.)}

Pada kasus Leni Mathul Kasanah, Majelis Hakim memberikan putusan pidana kepada terdakwa yakni penjara selama 1 tahun 1 bulan, karena ia secara sah dan meyakinkan, sesuai dengan Pasal 193 Ayat (1) KUHAP, telah melakukan tindak pidana Penipuan sesuai dengan yang diatur dalam Pasal 378 KUHP. Sesuai dengan dakwaan penuntut umum, namun hakim melihat beberapa faktor ketika menjatuhkan putusan, faktor-faktor yang dapat meringankan penjatuhan pidana kepada Leni Mathul Kasanah, bahwa ia telah mengakui dan menyesali perbuatannya. 
Berdasarkan fakta-fakta di persidangan, dengan hadirnya para saksi, terdakwa, serta barang bukti yang dipakai oleh terdakwa dalam melakukan kejahatan, terdakwa terbukti secara sah dan meyakinkan, sesuai dengan Pasal 183 KUHAP. Terdakwa telah melakukan tindak pidana Penipuan, sesuai yang diatur dalam Pasal 378 KUHP. Serta fakta-fakta yang terungkap selama proses persidangan juga membuktikan bahwa terdakwa cakap menurut hukum dan tidak berada di bawah pengampuan (curatele), serta tidak ditemukan alasan pembenaran terhadap apa yang telah dilakukan oleh terdakwa, sehingga terdakwa dapat mempertanggung jawabkan perbuatannya tersebut. Pertimbangan Majelis Hakim dalam menjatuhkan Pidana terhadap Leni Mathul Kasanah dalam putusan Nomor 482/Pid.B/2018/PN Blt telah sesuai dengan terpenuhinya semua unsur pada Pasal 378 KUHP, serta adanya minimal 2 alat bukti, yakni keterangan saksisaksi serta keterangan terdakwa, beserta barang bukti yang dipakai terdakwa dalam melakukan perbuatannya sesuai dengan Pasal 183 KUHAP. Selain itu pertimbangan Hakim dalam menjatuhkan sanksi pidana telah mempertimbangkan berbagai hal yang dapat memberatkan penjatuhan pidana, dan juga hal-hal yang memperingan penjatuhan pidana. Keadaan yang memberatkan dalam Putusan Nomor 482/Pid.B/2018/PN Blt yaitu perbuatan terdakwa meresahkan masyarakat dan merugikan saksi Nanda Irawan. Sedangkan keadaan yang meringankan dalam Putusan Nomor 482/Pid.B/2018/PN Blt yaitu terdakwa mengakui dan menyesali perbuatannya.

\section{PENUTUP}

Surat dakwaan (acte van verwizing) yang dibuat oleh Penuntut Umum dengan Nomor Registrasi Perkara PDM- 201/BLTAR/Epp.2 /12/2018 sudah memenuhi syarat formal dan materiil dari surat dakwaan sesuai Pasal 143 Ayat (2) KUHAP, serta tuntutan (requisitoir) yang dibuat oleh Penuntut Umum dengan Nomor Registrasi Perkara PDM 201/BLTAR/Epp.2/12/2018 telah sesuai dengan ketentuan-ketentuan dalam membuat surat tuntutan.

Demi terwujudnya kepastian hukum materiil yang mengatur mengenai pelaku tindak pidana, hendaknya diharapkan kepada seluruh aparat penegak hukum, khususnya jaksa dan hakim dalam menangani kasus tersebut, jaksa dan hakim harus memperhatikan secara cermat dan jelas mengenai unsur-unsur dalam setiap pasal karena jika salah dalam menerapkan pasal maka hal tersebut batal demi hukum. Demi kepastian, keadilan dan kemanfaatan sebagaimana teori tujuan hukum, dalam memutus setiap perkara Majelis Hakim haruslah mempertimbangkan secara cermat dan jelas mengenai keterangan saksi, alat bukti dan hal-hal yang memberatkan dan meringankan si terdakwa sehingga diputuskan dengan seadil-adilnya. 


\section{DAFTAR PUSTAKA}

\section{Buku dan Jurnal:}

Abdullah, Jurnal Hukum: "Penafsiran Hakim tentang Perbedaan antara Perkara Wanprestasi dengan Penipuan", Puslitbang Hukum dan Peradilan Badan Litbang Diklat Kumdil MaRi, Bogor, 2012.

Adami Chazawi, Pelajaran Hukum Pidana I, Jakarta : PT Raja Grafindo Persada, 2010.

Adirwan Akbar, Tinjauan Yuridis terhadap Tindak Pidana Penipuan (Studi Kasus Putusan No. 1629/Pid.B/2014/PN.Mks.), Makassar: Universitas Hasanuddin, 2015.

Andi Hamzah, Delik-Delik Tertentu (Speciale Delicten) di Dalam KUHP, Jakarta: Sinar Grafika, 2010.

Bambang Waluyo, Pidana dan Pemidanaan, Jakarta : Sinar Grafika, 2004.

E. Y. Kanter, S. R. Sianturi, Asas - Asas Hukum di Indonesia dan Penerapannya, Jakarta: Storia Grafika, 2012.

Hari Sasangka dan Lily Rosita, Hukum Pembuktian dalam Perkara Pidana, Bandung: Mandar Maju, 2003.

Leden Marpaung, Asas-Teori-Praktik Hukum Pidana, Jakarta: Sinar Grafika, 2005.

Leden Marpaung, Proses Penanganan Perkara Pidana , Jakarta: PT. Sinar Grafika.

Moeljatno, Asas - Asas Hukum Pidana, Jakarta: Rineka Cipta, 2009.

Teguh Prasetyo, Hukum Pidana, Jakarta: PT. Raja Grafindo Persada, 2011.

Tim Penyusun Kamus Pusat Pembinaan dan Pengembangan Bahasa, Kamus Besar Bahasa Indonesia, Jakarta: Balai Pustaka, 1990.

Wirjono Prodjodikoro, Asas-Asas Hukum Pidana di Indonesia, Bandung: PT Eresco, 1986.

\section{Peraturan Perundang-Undangan:}

Undang-Undang Republik Indonesia Nomor 1 Tahun 1960 tentang Perubahan Kitab Undang-Undang Hukum Pidana (KUHP)

Undang-Undang Republik Indonesia Nomor 8 Tahun 1981 tentang Kitab UndangUndang Hukum Acara Pidana

Undang-Undang Republik Indonesia Nomor 11 Tahun 2012 tentang Sistem Peradilan Pidana Anak 